دراسة فاعلية برنامج (بدني وغذائي) على تحسين الكفاءة البذنية والفسيولوجية لاى الرجال بمنطقة الجوف بالمملكة العربية السعودية

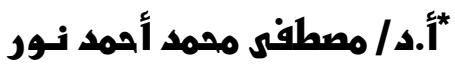

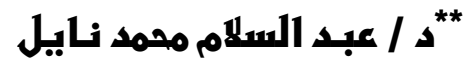

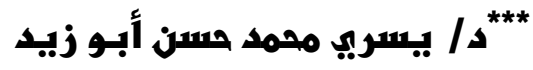
مقدمة ومشكلة البحث :

لقد تميـزت الآونـة الأخيـرة بالتقدم التكنولـوجي الهائـل حيث دخلت

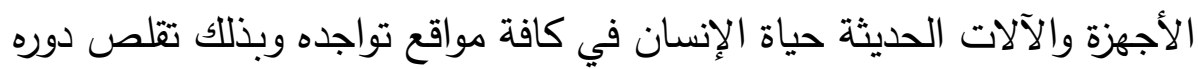

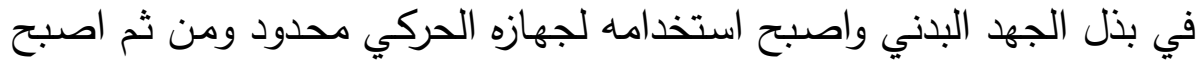

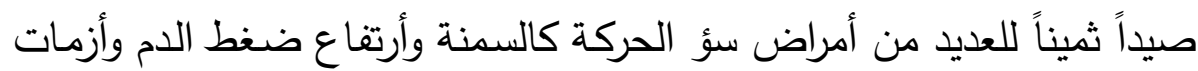

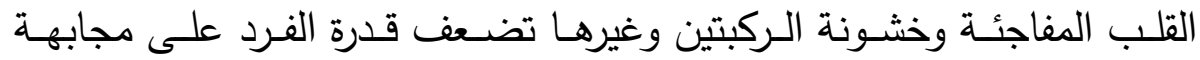
التغيرات المناخية منها ما هو حاد ومنها ما هو مزمن وتزكر ليلى شاهين انه كذلك.

تضعف القدرة على مجابهة المجهود البدني المفاجئ والذي قد يؤدى

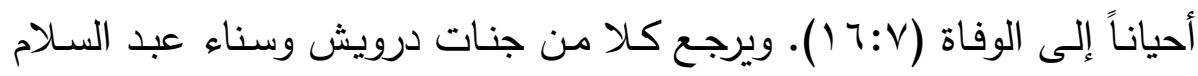

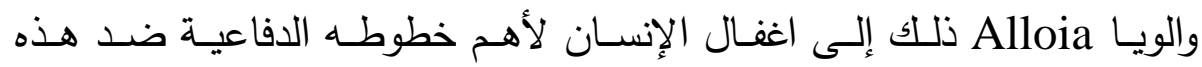

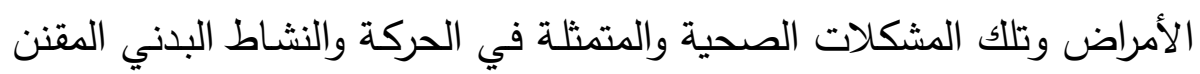

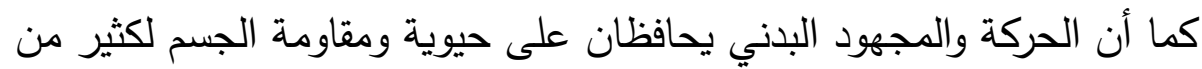

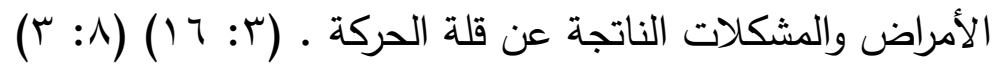

" أستاذ دكتور بعمادة السنة التحضيرية جامعة الجوف

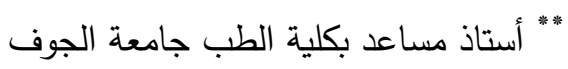
" " أستاذ مساعد بكلية التربية الرياضية بأبي قير جامعة الإسكندرية مجلة أسيوط لعلوم وفنون التربية الرياضية 
ويـكر "أمسين الخـولى، جنـات درويش، سـناء عبد اللسـلام" انـه قد حظيت الرياضــة منذ فجر التاريخ باهتمـام كبير مـن قبـل الثـعوب بـاختلاف أجناسـها ولغتهـا وقد حـث الإســلام على ممارسـة الرياضـة وضـرورة مزاولتهـا

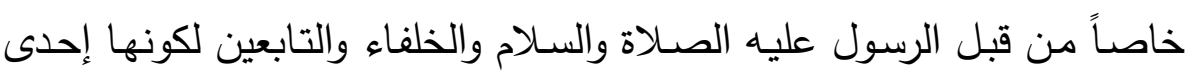
مسـبات النصـر وإنجـاز الفتوحـات وذكـر عليـهـ الصــلاة والســلام في حديثـة الثريف أن المؤمن القوى خير وأحب إلى الله من المؤمن الضعيف ودعا عمر بـن الخطاب الرعيـة إلى مزاولة بعض الأنشطة فقـال علموا أولادكم السـباحة والرماية وركوب الخيل والأجدر من ذللك أن الله عز وجل ذكر في كتابه العزيز

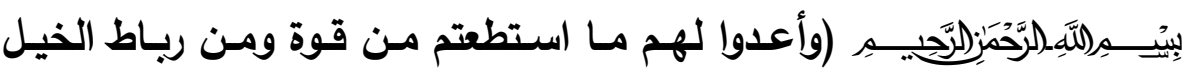
ترهبون بـه عدو الله وعدوكم) صدق الله العظيم (الأنفال: • ؟) وهذه دعوة من فئ الله عز وجل يحث المسلمين على الأعداد والتهيئة لمجابهـة المشقة والعنـاء والتعب الذي سيلاقونه عند ملاقاة العدو • ومن ثم كان الأهتمام بالرياضة وبذل الجهد البدني الذي يعود على الفرد بتحسين كفائتة البدنية والنفسية والصحية.

$(97: 1)(11: 4)$

ويـذكر "ثـلبى محمد شـلبىى" أن التمرينـات البدنيـة تعتبـر حجر الزاويـة

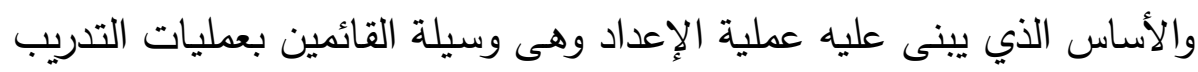

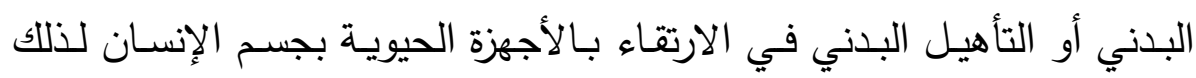
فيعتبرها الباحثون خط الدفاع الأول الذي يحمى به الإنسان من الوقوع في براثن أمراض ومشكلات سوء الحركة. (ع: • 7)

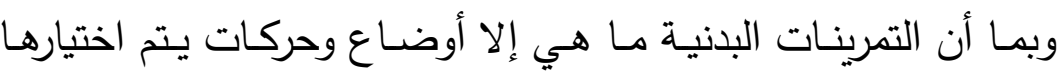

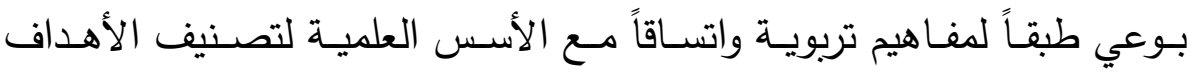

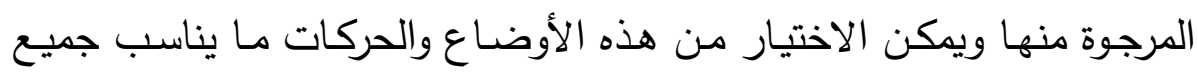
الأفراد والمراحل السنية والجنسـية لرفع مستوى لياقتهم البدنيـة أو الحركيـة أو هـئ

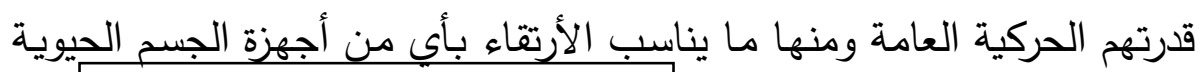

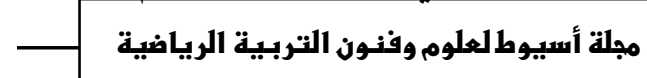


ومنها ما يعمل على تطوير وترقية وظائف الجهاز العضلي ن الجهاز الدوري

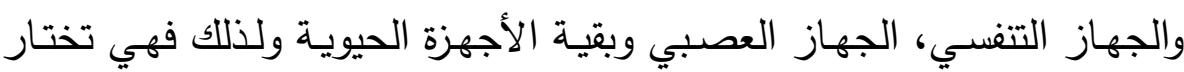

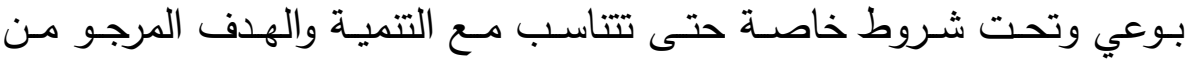
دراستها.

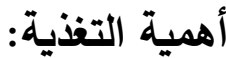

تعتبر التغذية والتمرينات البدنية هما حجر الزاوية والأساس الذي يبنى

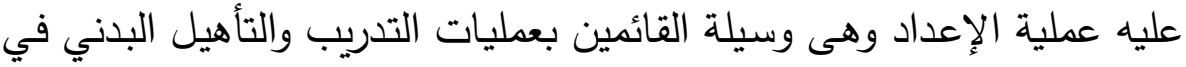

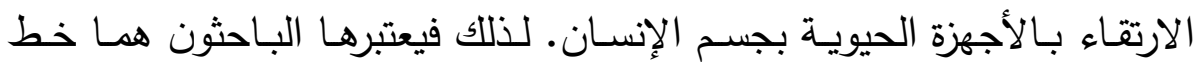

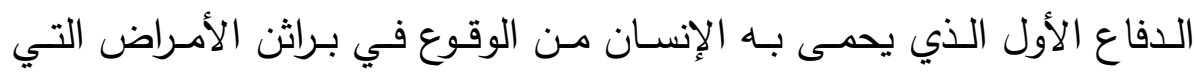

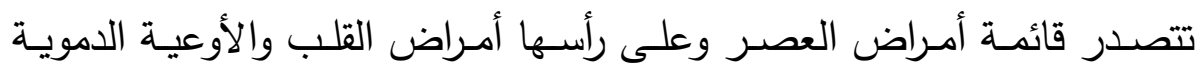

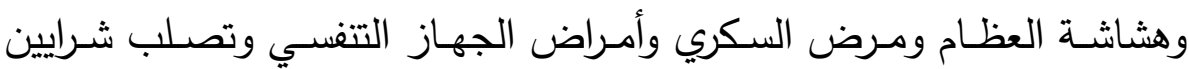
وغيرها.

والجدير بالذكر أن قلـة الحركـة وعدم الانتظـام في ممارسـة النشـاط

الرياضي وعدم إتباع النظام الغذائي السليم يؤدى على زيادة وزن الجسم كما الحال في السمنة الذي يؤدى بدوره إلى زيادة الدهون المترسبة في الأنسجة وكذللك الدهون الذائبة في الدم والتي تعمل على إعاقة العمل الحيوي للأجهزة

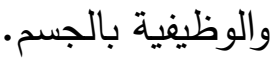

وفي هذه الدراسة سوف يتم تقنين برنامج تدريبي بدني وغذائي محددة سوف يتم تقنينها في البرنامج الغذائي المقترح ، وفيما يخص البرنامج البدني

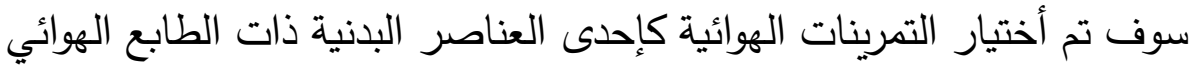
والذي له انعكاسه الإيجابي علي العينة المستهدفة من الدراسة. 


\section{Food Guide Pyramid}

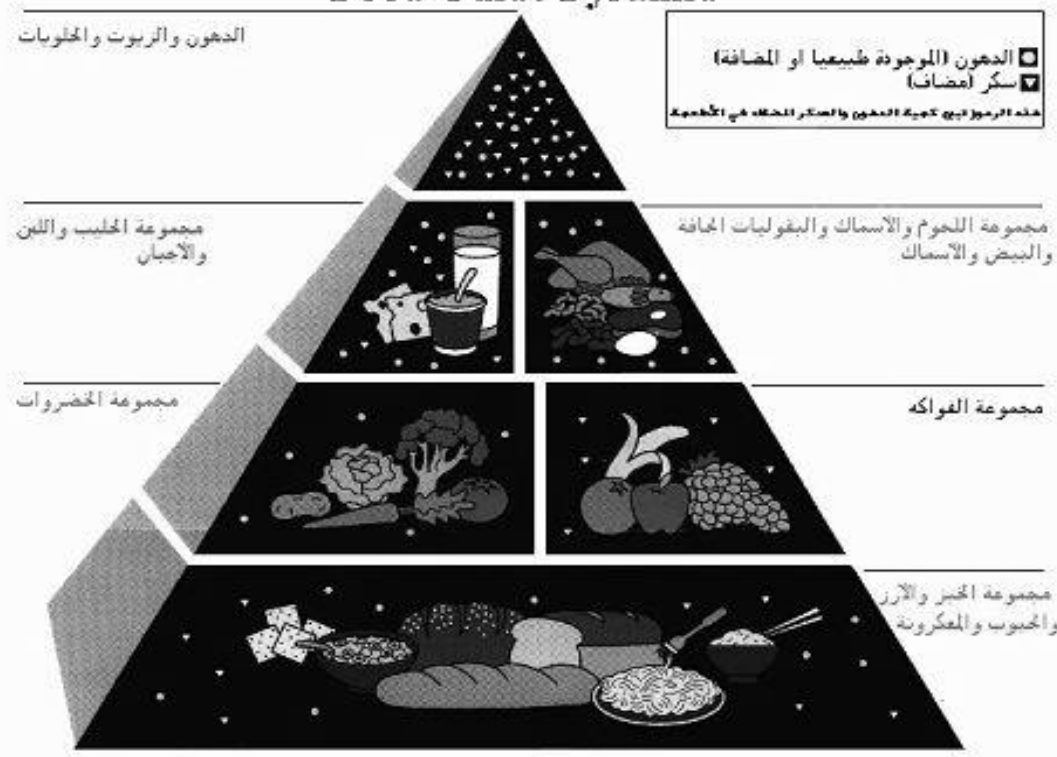

ولعل من اهم مـا قد يميز البرنـامج التدريبي المعترح عن مـا يتعاطساه الأفراد من فيتامينات ومقويات في صورة عقاقير طبية تساعدهم في مجابهة العبء البدني الغير معتاد أن البرنامج البدني المقترح قد يوظف حركة الجسم نفسه في الارتقاء بكافة أجززته الحيوية دون المساس بميكانيزم الجسم بالإضافة الجناف

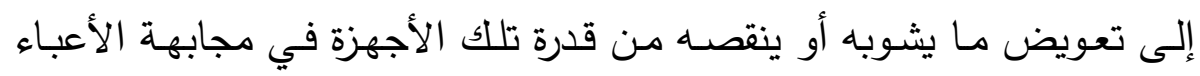
البدنية المفاجئة والغير معتادة والتى تمكنهـ من القيـام بإعماله اليوميـة بكفاءة

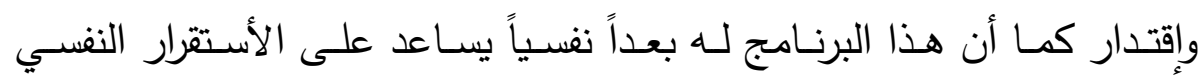

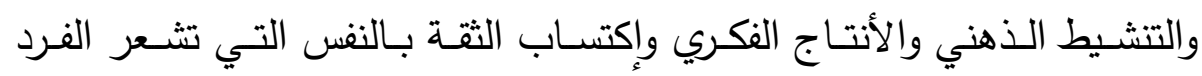
بإمكانية إنجازه لمناسك الحج والعمره على أكمل وجه. والجدير بالذكر أن البرنامج التدريبي مصمم ومقنن طبقاً لقدرات الأفراد

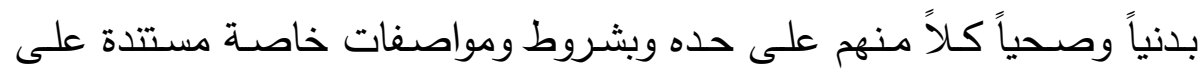
الأسس العلمية الحقائق والفسيولوجية. 
ويـرى الباحثون أن أداء مناسـك الحـج والعمرة تتطلب من الفرد البذل الثديد من المجهود البدني حيث الطواف حول الكعبة سبعة أشواط والسعى بين ونين الصفا والمروة سبعة أشواط والوقوف بعرفة ورمسى الجمرات وغيرها من المناسك

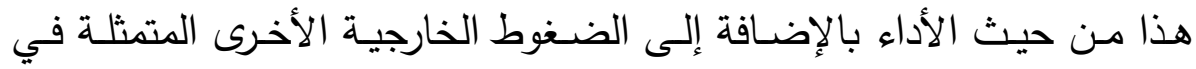

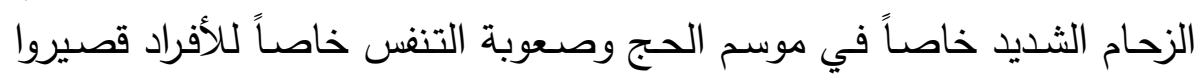

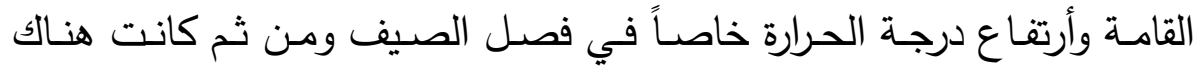
ضرورة تستوجب الأعداد لأداء هذه المناسك من الناحية البدنية والفسيولوجية لمجابهة هذا المجهود البدني ومتمشياً مع دعوة الله عز وجل للأعداد والتهيؤ في مواطن الجهاد والمشقة ولعل أداء مناسك الحج والعمرة من المواطن الكبرى لجهاد النفس.

لذا يرى الباحثون ضرورة أعداد برامج للتدريب البدني لأعداد تلك الفئة

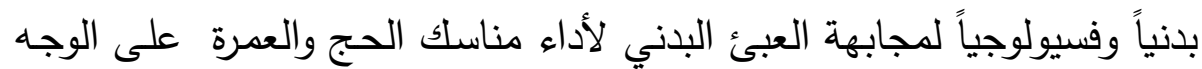
الذي به يتقبل الله عز وجل تلك اداء هذه الفريضة. أهداف الاراسة : بله التعرف على فاعلية البرنامج على تحسين الكفاءة البدنية والمتمثلة فى (التوافـق الكلـى للجســـ الرشـاقة؛ التوافـق بـين العـين واليـدين) والكفــاءة الفيسيولوجية والمتمثلـة فـى (وزن الجسـم ؛معـدل نـبض القلب فـى الراحـة والمجهود؛ زمسن تحمل المجهود بالدقيقة؛معدل نبض الأستشفاء بعد آو گو 7 دقائق) لدى الأفراد متوسطى العمر لأداء مناسك الحج والعمرة. فروض الدراسة : يفترض الباحثون أن ممارسة الإفراد متوسطي العمر للبرنامج التدريبي المقترح بصورة منتظمـة يؤدى إلى رفع كفاءتهم البدنية (التوافق الكلى للجسم؛

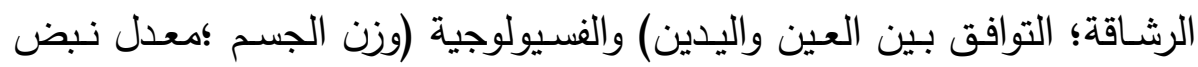

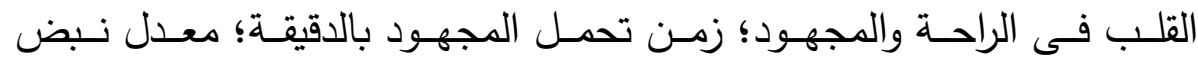
الأستشفاء بعد آو عو 7 دقائق) لأداء مناسك الحج والعمرة. 
إجراءات الدراسة :

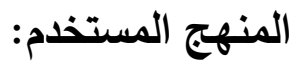

المنهج التجريبي باستخدام مجموعتين احداهما تجريبية والأخرى ضابطة

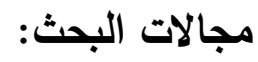

المجال المكاني: ملعب عمادة السنة التحضيرية.

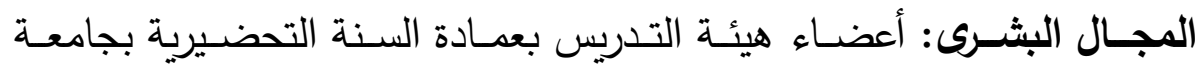
الجوف.

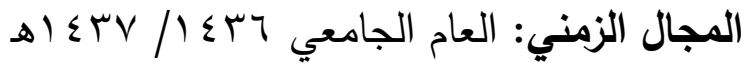
عينة الدراسة :

أجريــت الدراسـة على عينـة عمديـة مـن أعضـاء هيئة التدريس بعمـادة

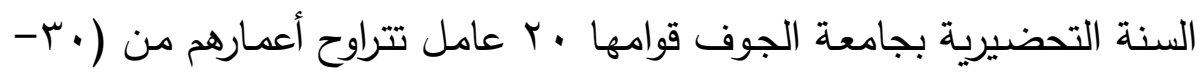

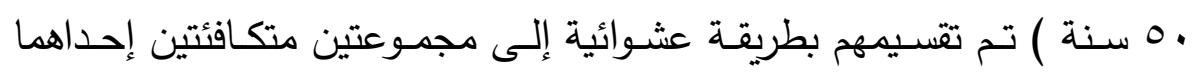
ضابطة قوامها • أفراد ولم يمارسوا البرنامج التدريبي المقترح والأخرى تجريبية

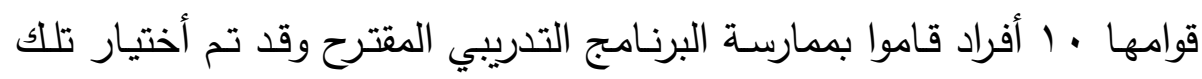
العينة للأسباب التالية:

- توافر صالة التدريب داخل الثركة الذين يعملون بها. - تقاربهم في المستوى الاجتماعي والثقافي. - لديهم الرغبة في تتفيذ البرنامج التدريبي المقترح وبانتظام.

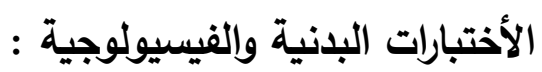

من خلال الدراسـة المسحية التى قام بها الباحثون للمراجع والأبحاث والدراسات فى مجال الأختبارات البدنية والفيسيولوجية ومقابلة الخبراء نم اختيار مجموعـة من الأختبارات التى تتمشى مـع طبيعة الأداء فى البرنـامج التدريبى

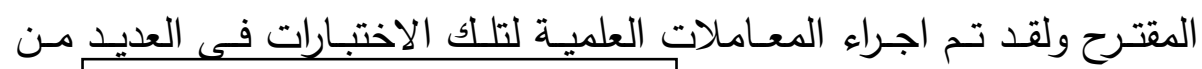

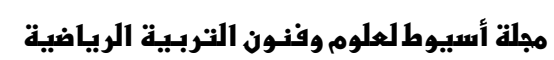


الدراسـات التى اثبتت صدق وثبات وموضوعية تلك الأختبارات وتمثلت تلك الأختبارات فى الأتى: - الأنى:

الأختبارات البدنية : الإلت

1- اختبار الوثب فوق الدوائر الرقمية لقياس التوافق الكلى للجسم

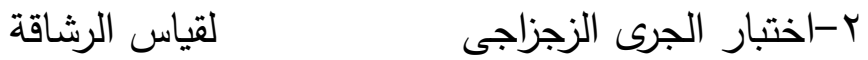
ب-اختبار رمى الكرة على الحائط لقياس التوافق بين العين واليدين الأختبارات الفيسيولوجية تم اجـراء اختبـار الجهـد البـدنى متعـدد المراحل على جهـاز السـير المتحرك لقياس المتغيرات التالية (معدل نبض القلب فى الراحة والمجهود؛ زمن تحمل المجهود بالدقيقة؛ معدل نبض الأستشفاء بعد آو گو ج دقائق). جاول (1)

المقارنة بين المجموعة الضابطة والتجريبية فى متغيرات البحث قبل إجراء التجربة والتجرية

\begin{tabular}{|c|c|c|c|c|c|}
\hline \multirow{2}{*}{ أفنبار } & \multicolumn{2}{|c|}{ المجمو عة التجرببـة } & \multicolumn{2}{|c|}{ المجمو عة الضابطة } & \multirow{2}{*}{ المعالجات الإمصائية } \\
\hline & $\varepsilon \pm$ & - & $\varepsilon \pm$ & - & \\
\hline r. $\leqslant q$ & $\vee . \vee \wedge$ & 91.0. & $1 . .7 r$ & ᄉ . .V. & وزن الجسم \\
\hline. .91 & r... & $\vee 9 .$. & r.7o & VV.r. & نبض الراحة \\
\hline $1 . . r$ & Y.IE & $1 \leq 9.9$. & $\varepsilon .00$ & 101.0. & نبض المجهود \\
\hline.$\wedge \mathrm{V}$ & r.VI & Irq.V. & r.tr & ITA.7. & 2ق \\
\hline . & Y.AO & 118.1. & $\varepsilon . Y \leqslant$ & $11 \mathrm{~V} . \mathrm{V}$ & ( \\
\hline..$\wedge \Lambda$ & $\varepsilon .+1$ & 1.5 .7$. & $\varepsilon .01$ & I.T.E. & 6 \\
\hline 1.11 & $\varepsilon . \varepsilon \varepsilon$ & IV.r. & E.T & $17 \ldots$ & زمن تحمل المجهود \\
\hline.$V V$ & $1 . \leqslant 0$ & 14.9. & $1.0 r$ & 1 T.1. & التوافق الكلى \\
\hline r.M & $.1 \times 9$ & 11.4. & $1.1 \varepsilon$ & $1 \cdot . v$ & الرشاقة \\
\hline. .11 & 1.10 & $1 \ldots$ & (1.T & $1 \cdot . r$ & التوافق بين العين \\
\hline
\end{tabular}


يتضـح مـن الجـدول (1) أنــه لـيس هنـاك فـروق معنويـة ذات دلالــة إحصائية بين المجموعتين التجريبية والضابطة فى جميع متغيرات البحث حيث

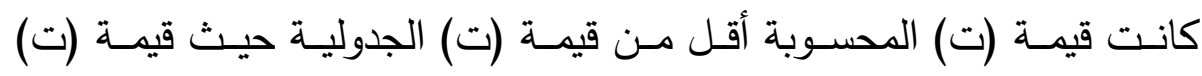

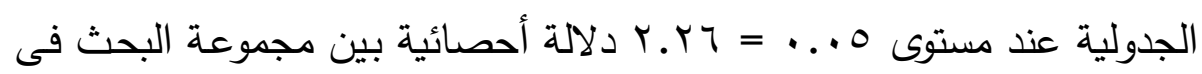
كلاً من موزن الجسم والرشاقة حيث كانت المحسوبة أكبر من (ت) الجدولية. أجهزة وأدوات القياس : موزن الجن

Tread mail جهاز الجري على السير المتحرك (الحصيرة الدوارة) - ميزان طبي لقياس الوزن. - رستاميتر لقياس الطول.

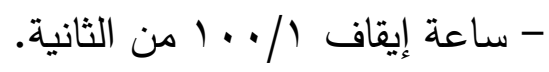

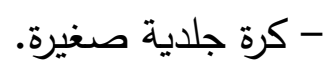

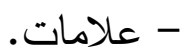

أسس اختيار تمرينات البرنامج : - أن تكون من النوع الحركي. - الابتعاد عن التمرينات التي تتطلب كتم النفس أو الحذق. - أن تؤدى التمرينات في حدود سعة الإنجاز البدني الذي حققها الفرد خلال ادائة لاختبار الجهد البدني الخاص به. - أن تتناول هذه التمرينات جميع المجموعات العضلية بالجسم.

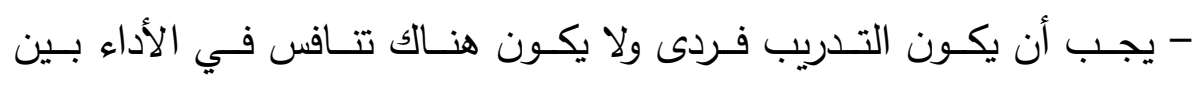
الأفراد. - الانتظام والاستمرار في التدريب. - ضـرورة أن يسـبق التمرينـات الأساسـية تمرينـات للإحمـاء لتتشـيط الـدورة الدموية وتهيئة المفاصل للعمل. 


\section{القياسات القبلية :}

تم إجراء القياسـات القبليـة على عينـة الدراسـة (المجموعـة الضـابطة التجريبية) قبل إجراء التجربة وتجميع البيانات اللازمة لكل فرد على حده. تطبيق البرنامج :

قامت المجموعة التجريبية بممارسة البرنامج التدريبي بطريقة التدريب

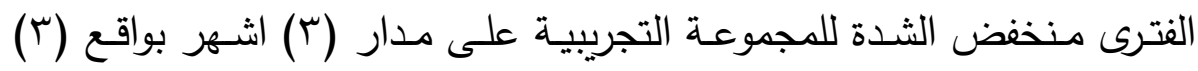

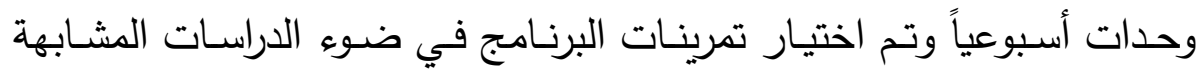

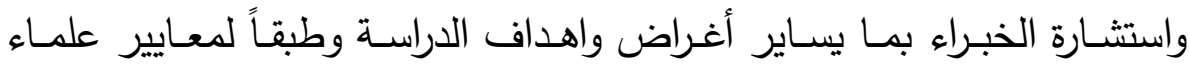

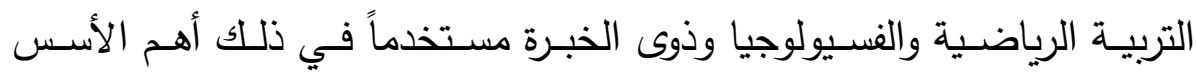
العلمية والتطبيقية وتضمن البرنامج على ثلاث أجزاء أساسية تمثلت في كلاً sis

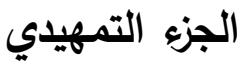

- - - مرينات الإحماء) والجزء الأساسي(تمرينات البرنامج التدربيى المقترح).

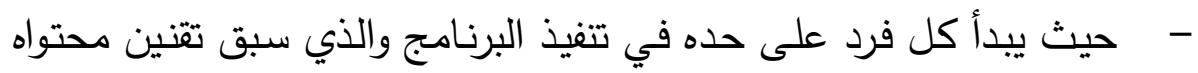

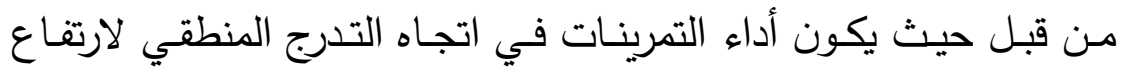
النبض. - كان يتم زيادة حجم أو شدة التدريب بناء على انخفاض بعض أو كل من معدل النبض. - كان يتم زيادة حجم أو شدة التدريب بناء على انخفاض بعض أو كل من

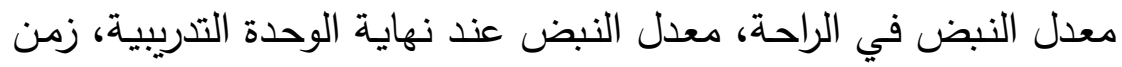
عودة النبض للراحة. - هذا وقد اعتبر الباحثون تلك المؤشرات الثلاثة أو بعضها دليل لتحسن لـاحة

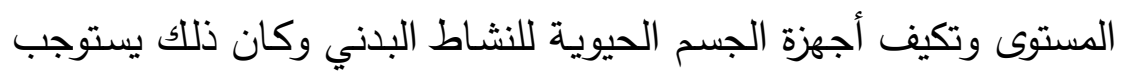


زيـادة سـعة العمل لدى الأفراد وكان يـتم ذلك بزيـادة حجم التدريب عن الوحدة التدرببيـة السـابقة عـن طريـق زيـادة معدل تكـرار التمـرين داخل المجموعة الواحدة. مع ملاحظة أن فترة الراحة بين المجموعات كان يزيد زمن أدائها تبعاً لزيادة زمن المجموعة وبالتالي الوحدة التدربيية. أما الجزه الأخير والختامي في البرنامج كان يتمثل في (تمرينات الاسترخاء) التى كانـت تلعـب دوراً هامـاً في التخلص مـن الحمـل الواقـع على الفـرد مـن الناحية الجسمانية والانفعالية. فى حين لم تمارس المجموعة الضابطة اى

$$
\begin{aligned}
& \text { برنامج تدريبى او اى نشاط رياضى منظم. } \\
& \text { القياسات البعدية : }
\end{aligned}
$$

تـم إجـراء القياسـات البعديـة لعينــة الدراســة (المجموعـة الضــابطة والتجريبية) بعد إجراء التجربة وذلك في نفس ظروف القياسات القبلية ومقارنتها ولإجراء المعالجات الإحصائية . نموذج لتمرينات البرنامج التدريبي المقترح : أولاًا : الإحماء

$$
\text { - - (وقوف) المشي أماماً. }
$$

- (وقوف) الجري في المكان مع دوران الذراعين أماماً ثم خلفاً. - (وقوف.ثبات الوسط) تبادل ثنى الجزع جانباً.

- (وقوف. فتحاً. الذراعان عالياً) ضـغط المنكبين خلفاً ثم ثنى الجذع أمامـاً أسفل والضغط. - 


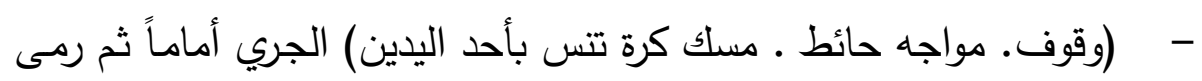

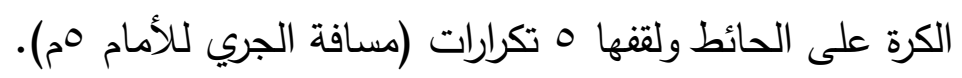

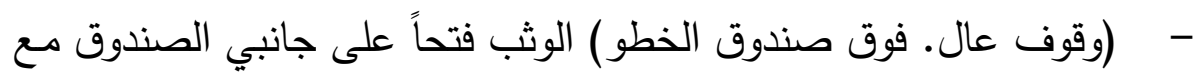
رفع الذراعين جانباً.

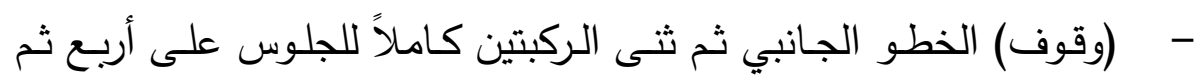

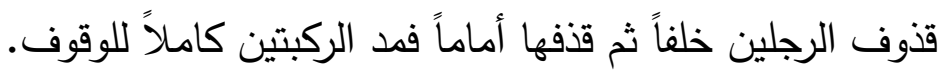
- - موقوف. مواجه علامات على الأرض) الجري الزجزاجى بين العلامات.

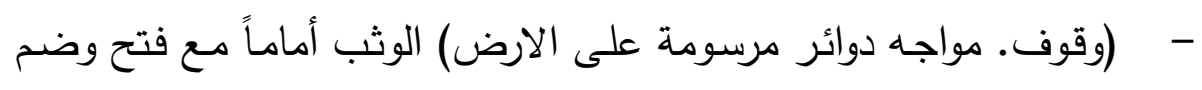
القدمين. - (وقوف) الجري المكوكي (المسافةه متر).

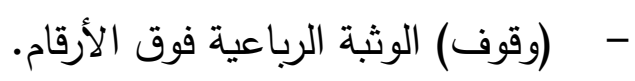

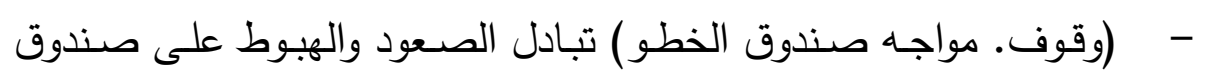
الخطو.

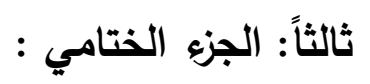

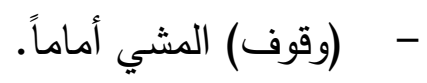
- - م المقوف) المرجحة الأمامية. - - موقوف) المرجحة العمودية مع رفع العقبين عالياً. - - م (وقوف) المرجحة بزاوية.

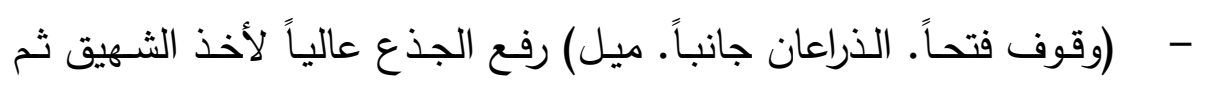
خفض الجذع مرة أخرى ببطء لأخراج الزفير.

جدول (r) ( ) - (r) 
rT.

المقارنة بين القياس القبلى والبعدى فى متغيرات البحث لدى المجموعة التجريبية

\begin{tabular}{|c|c|c|c|c|c|c|c|c|}
\hline \multirow{2}{*}{ المئوبسبة } & \multirow{2}{*}{ قالفـــــروة "ت } & \multicolumn{2}{|c|}{ الفــــــروقة } & \multicolumn{2}{|c|}{ القيـاسر البعدي } & \multicolumn{2}{|c|}{ القيــاس القبلي } & \multirow{2}{*}{ المعالجاتئة } \\
\hline & & الانــراف & المتوسطط & الانـهراف & المتو سطط & الانــراف & المتو سلط & \\
\hline$\% 0$. Yo & $* * \vee . .7$ & r.10 & $\varepsilon . \Lambda$. & T. $\Sigma \Gamma$ & Ат.े. & V.VA & 91.0. & وزن الجسم \\
\hline$\% \vee .9 \vee$ & $* * \backslash \wedge . \wedge \mid$ & $1 . .7$ & ז.r. & $1.7 \varepsilon$ & VY.V. & r... & vq... & نبض الراحة \\
\hline$\% ч . \vee \leq$ & $* * I V . r \leq$ & 1.10 & $1 \cdot .1$ & 1.94 & 1т9.1. & r.l $\leq$ & $1 \leq 9.9$ & 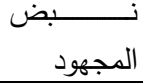 \\
\hline$\% \wedge . \wedge \vee$ & $* *$ * .70 & $1 . r V$ & 11.0 & $r . \leqslant r$ & IN.r. & Y.VI & Irq.V. & 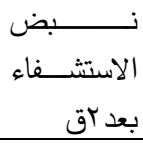 \\
\hline$\% 9 . \wedge r$ & $* * 10 . .7$ & T.EY & 11.0 & T.OV & $1 \cdot 0.7$ & Y.10 & 118.1. & 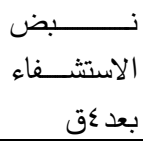 \\
\hline$\% \wedge . \vee$. & $* * 17.70$ & $1 . V r$ & 9.1 . & 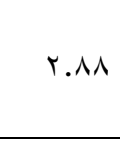 & 90.0. & $\varepsilon . .1$ & $1 \cdot \varepsilon .7$. & 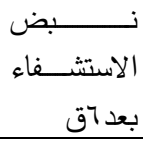 \\
\hline \%оr.r. & $* * 9.1 \leq$ & $r . .7$ & $9 .$. & $7 . \leqslant 1$ & r..r. & $\varepsilon . \leqslant \varepsilon$ & IV.r. & 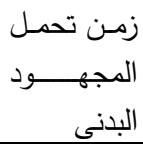 \\
\hline$\% r \leq . \wedge 1$ & $* * 11 \ldots 1$ &. $.9 r$ & T.Y. & $1 . .7$ & q.V. & $1 . \leqslant 0$ & ir.q. & للجسم التوافق الكلى \\
\hline$\%$ YI. & $* * 1 \leq .90$ &. .01 & Y.E. &..$\leqslant \wedge$ & $\wedge . \wedge$. &..$\vee 9$ & $11 . r$. & الرشاقة \\
\hline$\% ч \varepsilon$ & $* * I V . r \leq$ & $1.1 \mathrm{~V}$ & 7.ร. & $1 . r 4$ & $17 . \varepsilon$. & 1.10 & $1 \ldots$ & التوافــق بــين \\
\hline
\end{tabular}

$$
\text { قيمة (ت) الجدولية عند 0. }
$$

يتضـح من الجدول رقم (Y) وجود فروق معنويـة ذات دلالة إحصـائية

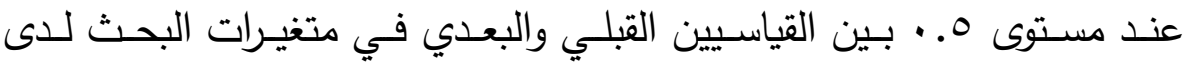

المجموعة التجريبية لصالح القياس البعدي.

جدول (r)

المقارنة بين القياس القبلى والبعدى فيى متغيرات البحث لاى المجموعة الضابطة 


\begin{tabular}{|c|c|c|c|c|c|c|c|}
\hline \multirow{2}{*}{ قبيمة "ت" } & \multicolumn{2}{|c|}{ الفُروق } & \multicolumn{2}{|c|}{ القياس البعدي } & \multicolumn{2}{|c|}{ القياسر القبليي } & \multirow{2}{*}{ المعالجاتية } \\
\hline & الانــراف & المتوسط & الانــراف & المتوسط & الانـمراف & المتوسط & \\
\hline $0 . \varepsilon 1 * *$ & $1 . .1$ & 1.10 & $11 . . \varepsilon$ & 11.00 & $1 . .7 r$ & ง..ข. & وزن الجسم \\
\hline $1.9 \pi$ & $.9 \mathrm{~V}$ & 1.0 & r.7^ & $\checkmark V . \Lambda$. & $r .70$ & VV.T. & نبض الراحة \\
\hline $7.0 \mathrm{~V} * *$ & T.IT & $\varepsilon . \varepsilon$. & $\varepsilon .70$ & 100.9 & $\varepsilon .00$ & 101.0 & المجهود \\
\hline$|1 . r| * *$ & 1.1. & r.9. & $r .1 \leq$ & ITr.o. & אזד & I YA.7. & 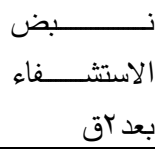 \\
\hline q. $\ \leqslant * *$ & 1.01 & $\varepsilon . \varepsilon$. & $\varepsilon . r$. & Irr.l. & $\varepsilon . Y \leqslant$ & IIV.V. & بعد الاستثـــــــــاء \\
\hline $11.11 * *$ & $1 . \varepsilon 1$ & $0 .$. & $0 . . \varepsilon$ & 1. A. $\leq$. & $\varepsilon .01$ & I.T.E. & 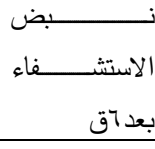 \\
\hline$r . . V$ & $1 . \leqslant 1$ & r... & $\varepsilon .0 \mathrm{~V}$ & 17.r. & E.rT & $17 .$. & زالمجهود بدنى تحـــل \\
\hline 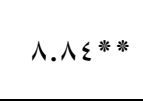 & $\cdot . \wedge r$ & r.r. & $1 . r 0$ & $1 \leq . \varepsilon$. & $1.0 Y$ & Ir.1. & اللجسم الكق الكلى \\
\hline $7.11 \% *$ & $1 . r 0$ & T.Y. & $1 . r$. & 14.9. & $1 . r \varepsilon$ & $1 \cdot . v$. & الرشاقة \\
\hline $0 . r \leq * *$ & $.9 \mathrm{~V}$ & 1.7 & $1 . r 4$ & $\wedge .7$. & I.rT & I..r. & العين واليدين \\
\hline
\end{tabular}

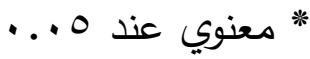

قيمة (ت) الجدولية عند 0.

يتضـح مـن الجدول (ب) وجـود فروق ذات دلالـة معنويـة عند مسـتوى

1 . . . لصالح القياس القبلي في جميع المتغيرات فيما عدا نبض الراحة وزمن

تحمل المجهود البدنى .. مما يشير إلى انخفاض الحالة البدنية والفسيولوجية

لاى أفراد المجموعة الضابطة.

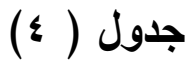

المقارنة بين المجموعتين التجريبية والضابطة في متغيرات البحث للقياس

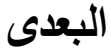




\begin{tabular}{|c|c|c|c|c|c|c|c|}
\hline \multirow{2}{*}{ قبهة "تـ } & \multicolumn{2}{|c|}{ الفُروز } & \multicolumn{2}{|c|}{ القباسر البهدي } & \multicolumn{2}{|c|}{ القباسر القبلي } & \multirow{2}{*}{ إمعالجات إمصائبةت } \\
\hline & الانـمراف & المتوسط & 11نـمراف & المتو ستط & 118ـمراف & المتوبسط & \\
\hline..$\leqslant 7$ & $\varepsilon . \varepsilon$ & $1 . \wedge 0$ & $11 \ldots \varepsilon$ & $\wedge \wedge .00$ & T.ET & А૫.V. & وزن الجسم \\
\hline$\varepsilon . \vee 9$ & $1 . r V$ & 7.1. & 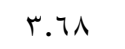 & 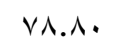 & $1.7 \varepsilon$ & VT.V. & نبض الراحة \\
\hline 1.1. & 1.09 & 17.1. & $\varepsilon .70$ & 100.9. & 1.94 & 1 & نبض المجهود \\
\hline $9 . V \leqslant$ & $1 . \Sigma V$ & $1 \leqslant . \mu$. & r.l & . & r. & IN.Y. & نبض الاستشـفاء \\
\hline$q . \leqslant V$ & $1 . V \varepsilon$ & 17.0. & E.Y. & ITr.l. & r.ov & 1.0 .7 & نبض الاستشـفاء \\
\hline V..r & I.N & 1Y.9. & $0 . . \varepsilon$ & 1.^.乏. & 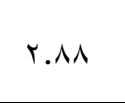 & 90.0. & نبض الاستشـفاء \\
\hline$\varepsilon . \wedge \vee$ & r.01 & IT.Y. & $\varepsilon .0 \mathrm{~V}$ & $1 \varepsilon \ldots$ & $7 . \Sigma \wedge$ & YT.Y. & 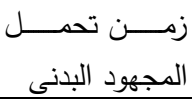 \\
\hline 1.77 & $0 \leqslant$. & V.E.- & סח. & $\mid \varepsilon . \varepsilon$. & $1 . .7$ & q.V. & 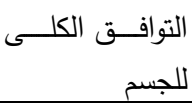 \\
\hline $1 . .10$ &.$\Sigma$ & $\varepsilon .1 \cdot-$ & $1 . r$. & 14.9. & $\because \leq 0$ & $\wedge . \wedge$. & الرشاقة \\
\hline $1 T . v q$ & $.0 \mathrm{~V}$ & $\vee . \wedge$. & דצ & ᄉ. 7 . & דצ & 17.5. & التوافق بين العين \\
\hline
\end{tabular}

$$
\text { قيمة (ت) الجدولية عند ه. . }
$$

يتضح من الجدول وجود فروق ذات دلالة معنوية عند مستوى ا ... .

من جميع المتغيرات البدنية والفسيولوجية لصالح المجموعة التجريبية . 
جدول (0)

النسب المئوية للتحسن لمتغيرات البحث لكل من المجموعة التجريبية والضابطة

\begin{tabular}{|c|c|c|}
\hline المجمو عة الفابطة المئوبة & 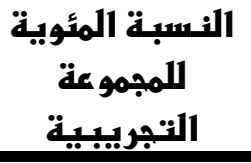 & معالجات إحصائية \\
\hline$\%$ \%.IT & $\% 0$. ro & وزن الجسم \\
\hline$\% 1.9 \leq$ & $\% \vee .9 \vee$ & نبض الراحة \\
\hline$\%$ \%.q. & $\%$ \%.V & نبض المجهود \\
\hline$\%$ \%..r & $\% \wedge . \wedge \vee$ & نبض الاستشفاء بعد آ \\
\hline$\%$ \%.V & $\% 9 . \wedge r$ & نبض الاستشفاء بعد قق \\
\hline$\% \varepsilon . \wedge \varepsilon$ & $\% \wedge . \vee$. & نبض الاستشفاء بعد آق \\
\hline$\% \backslash$ Y.० & \%०r.ru & زمن تحمل المجهود البدنى \\
\hline$\% 19 . .1$ & 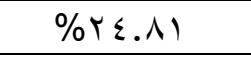 & التوافق الكلى للجسم \\
\hline$\% Y \cdot .07$ & $\%$ \%.$\varepsilon r$ & الرشاقة \\
\hline$\% 10.79$ & $\%$ \% & التوافق بين العين واليدين \\
\hline
\end{tabular}

يتضـح مـن الجدول رقم (0) في النسـب المئويـة حيث جـاءت نسـب المئويـة للتحسن لصـالح المجموعـة التجربيـة وجاءت نسبة التأخر في صـالح المجموعة الضابطة لعدم ممارستها لآي برنامج تدريبي • مناقشة النتائج : 1 - زمن تحمل المجهود البلني بالدقيقة يتضح من الجدول رقم (؟، ک) وجود فروق معنوية ذات دلالة إحصائية بين المجموعتين الضابطة والتجريبية في زمن تحمل المجهود البدني بالدقيقة وذلك لصـالح المجموعـة التجريبية حيث كان هناك زيـادة في زمن تحمل المجموعـة التجريبية للمجهود البدني • ويرجع الباحثون ذلك إلى ممارسـة تلك المجموعة للبرنامج التدربي المقترح الذي يشمل على أحمال تدريبية ذات الطابع الهوائي الذي من شأنه العمل على تحسين كفاءة الجهازين الدوري والتنفسي وهذا يتفق

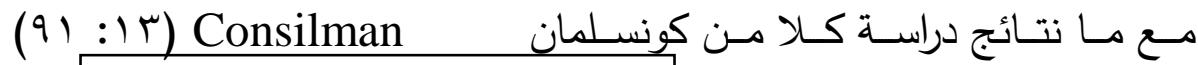
مجلة أسيوط لعلوم وفنون التربية الرياضية 


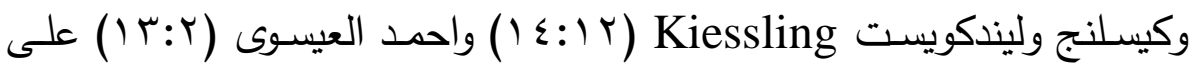
أن هذه النوعية من التدريبات تعمل على رفع كفاءة الفرد وتمكنه من اداء الجهد المطلوب بصورة أفضل ولفترة زمنية اطول وبنفس الكفاءة.

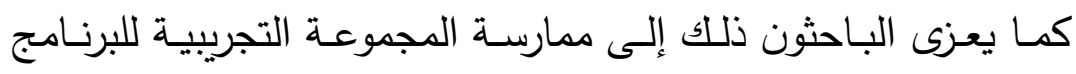

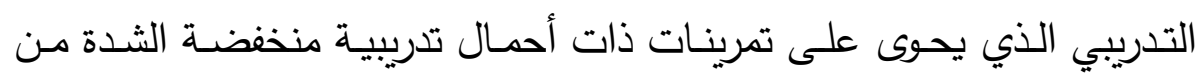

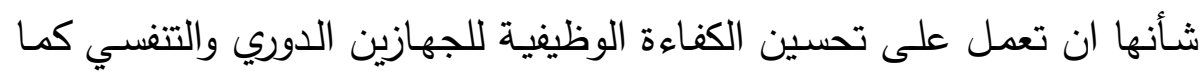

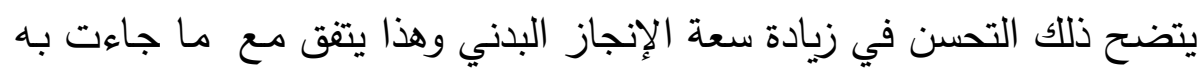

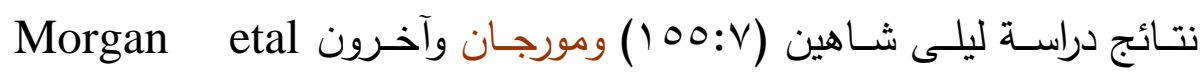

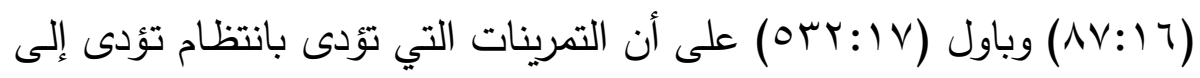

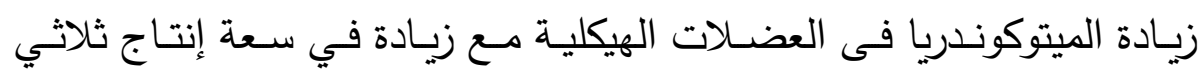
فوسفات الادينوزين وهو مركب كميائى غنى بالطاقة ولا بد من إعادة تكوينه حتى يتمكن الإنسان من بذل المجهود.

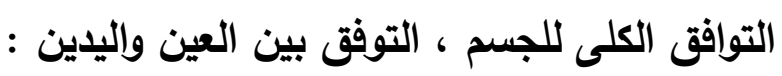

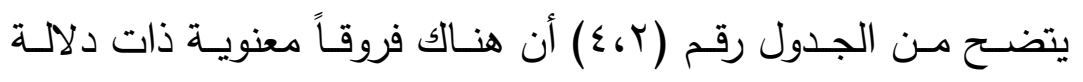

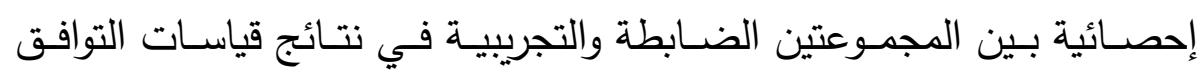

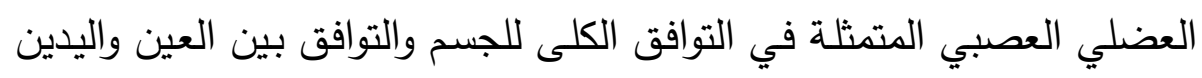

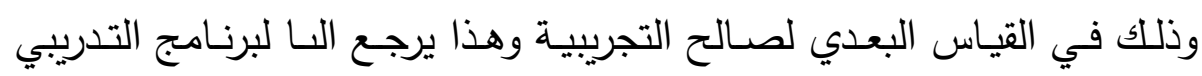

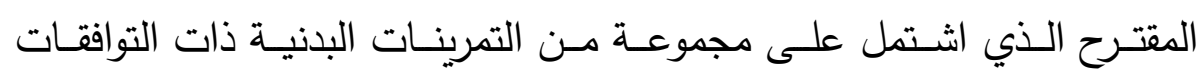

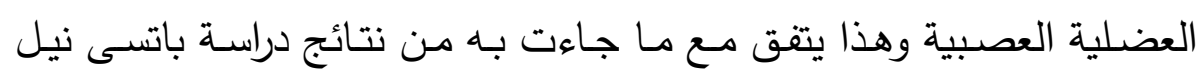
Patsy neal

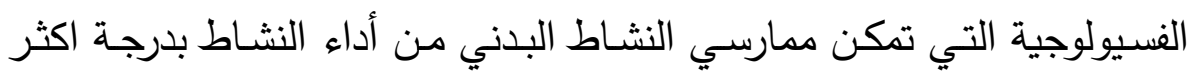
فاعلية توجد هناك تغيرات تطرأ على كفاءة الجهاز العضلي تمكنه من الأداء

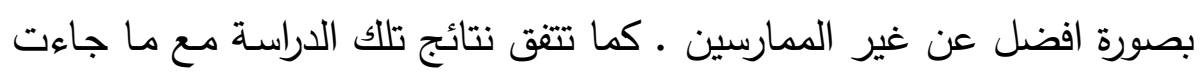

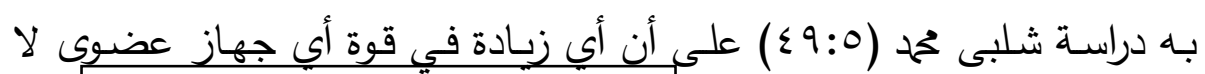
مجلة أسيوط لعلوم وفنون التربية الرياضية فئ جنية 
تحدث إلا نتيجة لإثارة اكبر واشد من الإثارة المعتاد عليها هذا الجهاز العضوى في نشاطه اليومي العادي لذا كان يتم التدريب بواقع ثلاث جرعات أسبوعيا

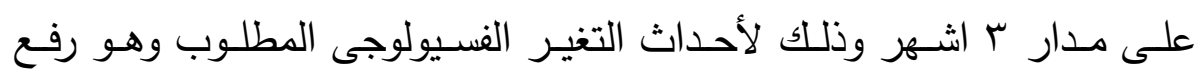
الكفاءة الوظيفية للمسارات العصبية التي تربط بين الجهازين العضلي والعصبي

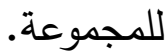

الرشاقة :

يتضح من الجدول (Y، §) أن هناك فروقاً معنوية ذات دلالة إحصائية

بين المجموعتين الضـابطة والتجريبية لصـالح المجموعة التجريبية في اختبار الرشاقة ويرجع الباحثون ذلك إلى ممارسة المجموعة التجريبة للبرنامج التدريبي الذي احتوى على مجموعة من التمرينات التي كانت تؤدى بقدر كبير من الاقة

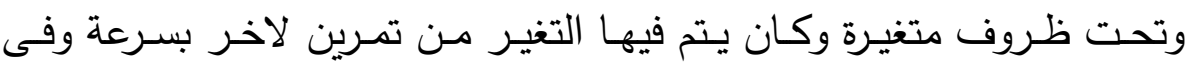
اتجاهات مختلفة وبأحمال تدربية منخفضة الثدة كان من شأنه تحسن مستوى لهري الرشاقة لتلك المجموعة مقارناً بالمجموعة الضابطة وهذا يتفق مع ما جاءت بـه

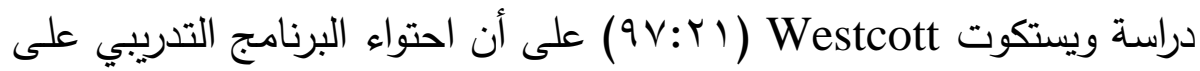
هـذه النوعيـة مـن التمرينـات مـن شـأنه يعمـل على تطـوير الرشـاقة والتوافق العضلي مما يزيد من مستوى قدرة الفرد الحركية.

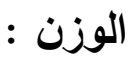

يتضـح مـن الجـدول رقم (Y، \& ) أن هنـاك فروقـاً معنويـة ذات دلالــة إحصـائية بـين المجمـوعتين الضـابطة والتجريبيـة فـي وزن الجسـم لصـالح المجموعة التجريبية وذلك في القياس البعدي ويرجع الباحثون ذلك إلى ممارسة المجموعة التجربيية للبرنامج التدربي المقترح ذوالصبغةالهوائية الذي من شأنه العمل على أكسدة المواد الدهنية المترسبة في أنسجة الجسم والزائدة فى الدم

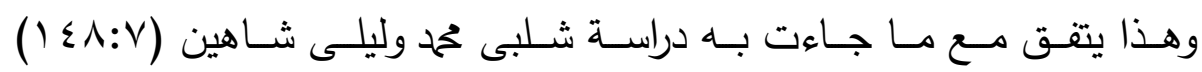

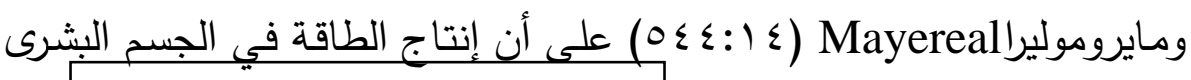

\section{مجلة أسيوط لعلوم وفنون التربية الرياضية}


فـى بدايـة النشـاط يعتمـد على جلوكوز الـدم بعـد تحويـل المـواد النشـوية إلى جلوكوز ثم يلجـأ الجسم بعد ذلك إلى إنتاج الطاقـة مـن خـلال تمثيل المـواد

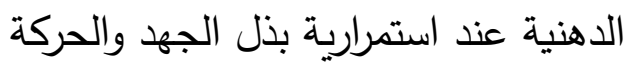

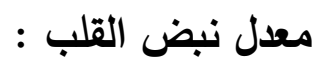

يتضـح مـن الجدول رقم (ع، Y) انخفـاض معـدل نـبض القلب لـدى المجموعة التجربية سواء في الراحة أو عند بذل أقصى مجهود بدني بالمقارنة بالمجموعة الضـابطة التي ثبت لديها معدل نبض القلب وكان الانخفاض في النـبض لـدى المجموعـة التجريبيـة ذو دلالــة معنويـة ممـا يـدل على التـأثير الإيجابي للبرنامج المقترح الذي مارسته المجموعة التجرببية في التأثير على تحسين معدل نبض القلب.

ويعتبر الباحثون هذا الانخفاض في معدل القلب في الراحة ذو قيمـة

حيوية كبيرة في تحسين امداد القلب بالأكسجين حيث تزداد فترة انبساط عضلة

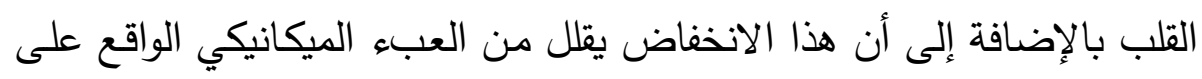
القلب حيث يقوم القلب بالواجبات المكلف بها ولكن بعدد ضربات اقل مما يؤكد

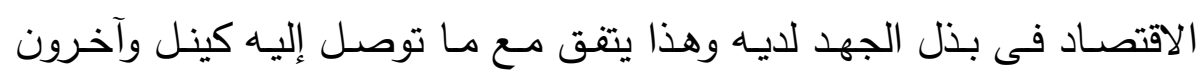
Kannel etal Desehryver etal سواء في الراحة أو بذل النشاط البارا سمبتاوى نتيجة ممارسة التدريب البدني .

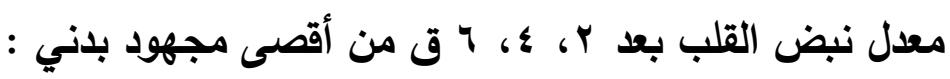

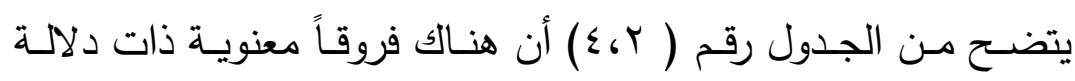
إحصائية بين المجموعتين الضابطة والتجريبية في معدل نبض القلب بعد با، ع، 7 ق من أقصى مجهود بدني القياس البعدي وكانت هذه الفروق صـالح المجموعة التجريبية ويرجع الباحثون انخفاض (تحسن) في معدل النبض بعد في في Y، ع، 7 ق من أقصى مجهود بدني لدى المجموعة التجربيـة إلى ممارستها

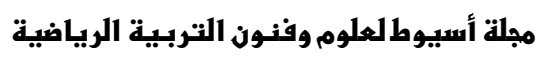


للبرنـامج التدريبي المقترح المتضمن على أحمال تدريبية منخفضـة الشدة ادت الى تحسين كفاءة القلب الوظيفية وجعلته يعمل بطريقة اقتصـادية ويدل هذا الانخفـاض في معدل النبض بعد أداء المجهود البدني على تحسـن مسـتوى وهي

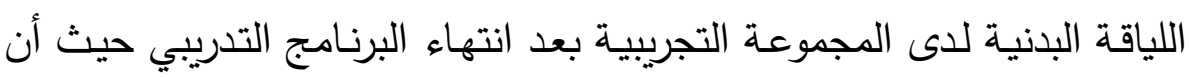
سـرعة العـودة للحالـة الطبيعيـة تعنىى سـرعة اسـتقرار الحالـة الوظيفيـة للجهاز العصبي المركزي وبالتالي سرعة عودة الأجهزة الحيويـة بالجسـ لحالتها قبل

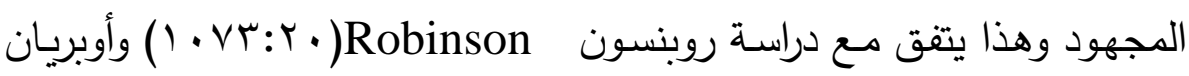

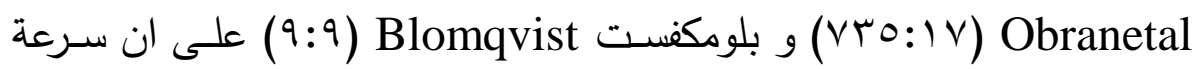
عودة النبض تعكس الحالة الجيدة التي أصبحت عليها أجهزة الجسم الحيوية

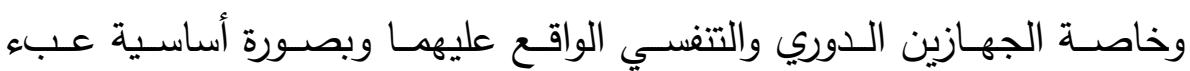
المجهود البدني المبذول. وحاهـ

يتضـح من الجداول (r،؛، م) تأخر مستوى المجموعة الضـابطة في متغيرات البحث (البدنية والفسيولوجية) لعدم مشاركتها البرنامج التدربي المقترح وعدم انتظامها في أي برنامج تدريبي آخر وهذا يتضـح من مقارنة نتائج تلك المجموعة فى القياس القبلى بنتائج القياس البعدى.

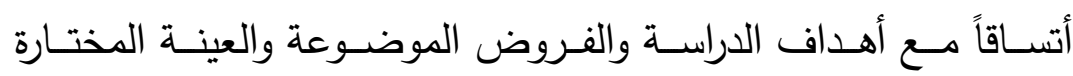
والمعالجات الإحصائية المستخدمة أمكن استتاج ما يلي :

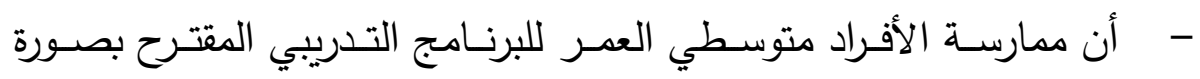
منتظمة يؤدى إلى رفع كفاءتهم البدنية والفسيولوجية والمتمثلة في تحسن

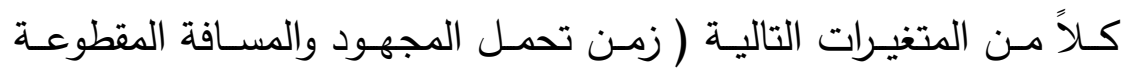

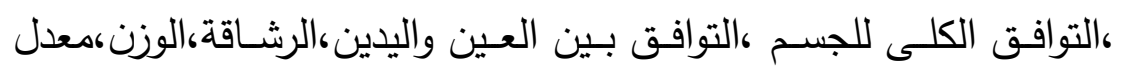
نبض القلب،معدل نبض القلب بعد Y، ع ، 7 ق من أقصى مجهود بدني التوصيات : (2 - n 
في حدود عينـة الدراسـة والإجـراءات التـي تمـت والمعالجـات الإحصـائية

المستخدمة والنتائج المتحصل عليها يتقدم الباحثون بالتوصيات التالية:.

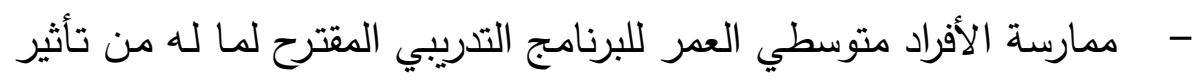
فعـال في تحسين الكفاءة الوظيفيـة لديهم وتـأهيلهم للوقايـة مـن الإصـابة بأمراض قلة الحركة. - - يوصسى الباحثون الأفراد متوسطي العمر الذي يقبلون على أداء مناسك لـك الحج والعمرة ممارسة البرنامج التدريبي المقترح.

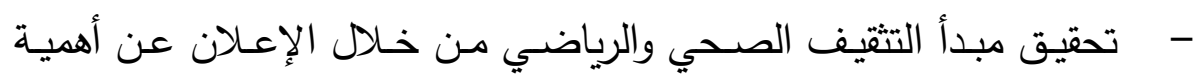
مزاولة البرامج الرياضية قبل الداء تلك المناسك وفتح المنشآت الرياضية والنوادي ومراكز الثباب أبوابها لمزاولة تلك البرامج.

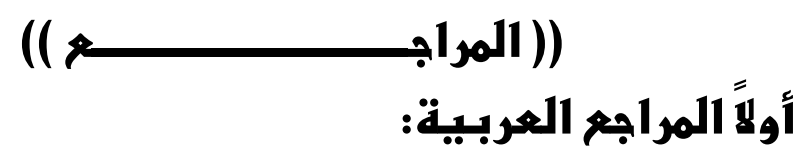

1 - أمين الخولى (90 99 1 ): الرياضة والحضارة الإسلامية، دار الفكر العربي. ץ - أحمد على العسيوى (990 199): تأثير برنامج تدريبي مقترح للياقة البدنية

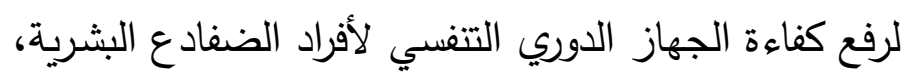
رسالة ماجستير غير منشورة، كلية التربية الرياضية للبنين جامعة الإسكندرية

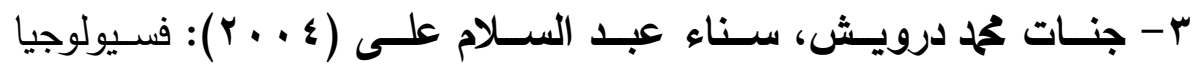
الرياضة، دار الطباعة، الطبعة الثالثة.

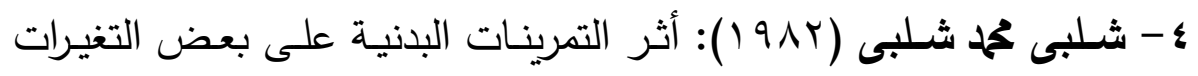
الفسيولوجية لتأهيل مـرض الشـريان التاجي للقلب، رسـالة غير منشـورة، كليـة التربيـة الرياضـية للبنين بالإسـكندرية، جامعة حلوان. 
ه - شلبى محمد شلبى (9 1 1 ) ): أثر برنامج مقترح من التمرينات البدنية على بعض المتغيرات الفسيولوجية والبدنية لمرضى السكر ،مجلة

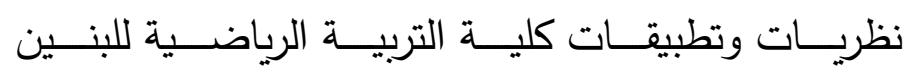
بالإسكندرية، العدد الخامس.

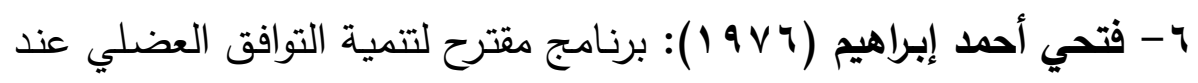
تلاميذ الصفين الخامس والسـادس الابتدائي (بنين) رسـالة ماجستير غير منشورة، كلية التربية الرياضية للبنين، أبوقير

$$
\text { الإسكندرية. }
$$

V- ليلى عبد الفتاح شـاهين (99V I ) ): تأثير برنامج تمرينات بدنية خاص

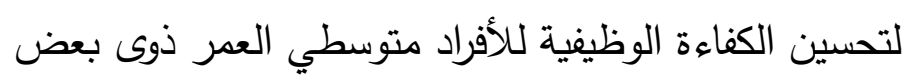
عوامل الخطة الإنتاجية. رسالة دكتوراه غير منشورة، كلية التربية الرياضية للبنين، جامعة الإسكندرية.

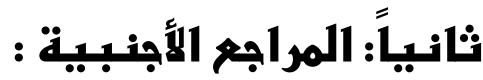

8- -Alloia,J.F(1981): Exercise and skeletal ,goral American Geriatric Society.

9- Bcomqvistyg (1965): The Frank lead exercise Electrocardiogram, acta .second. (suppl) .440 10- DeSchryver,C., Merrens, Srry Thangen Becsei,j. (1969): Effect of Traning on Hearts and Skeletal Muscle . Vol . 217. no.6.

11- Kannel ,W.B., and Dawber (1972): Therosclerosis as \& Pediatric Problem . Pediatr . 80 
12- Kiess Ling and Lundqvist,C.G (1970): Number and

Size of Skeletal Muscle Mitochondria inTrained Seden Tary Men. Mallmbrg Baltimore University Park Press.

13- Konsslman, Kras Now,S. (1995): Heart Diseases and Exercies

14- Malyer and Moller, J.H, (1995): Nicogossian, Arnauld Space Flight

15- Morgan To, Morriss .H.I, (1998): ExercisePhysiology Enery Enery Nutrition and Human Performance 2 nd .ed lea

16- O,Brien,k.p.,Lawrence (1997): Comparison During Angina Induced By Arrial Pacing. Circulation 39.

17- Paul , M.H.,( 1996): Cyclophorase System . Correlation of Cyclophorase Activity and Mitochondrial .Proc .Soc Exp . Biol .Med .79

18- Patsy, Peters. Q.K., (1983): Physical Fithness and Subsequent Myocardial Infraction in Healthy Workers, Jam 2249

19- Philip, Kpaul (1989): Cardiac Rehabilition Adult Fitness Febiger Philadel Phia. 
20- Robinson.T.R., (1997): Relation of Heart Rate and Systolic Blood New York . 307

21- West COH,W. (1993): Strength Traning and Blood Prusserrs Ponse Nurilus 2. 